Robayo, M. (2015] La canción social como expresión de inconformismo social y político en el siglo xx. Calle14, 11 (16) pp. 54 - 67

\title{
LA CANCIÓN SOCIAL COMO EXPRESIÓN DE INCONFORMISMO SOCIAL Y POLITICO EN EL SIGLO XX
}

\begin{abstract}
RESUMEN
Este artículo, producto de la tesis de maestría "El imaginario social y político presente en la canción social o protesta en Colombia durante el periodo comprendido de 1960 - 1970", muestra el papel preponderante que la canción protesta ha jugado en la historia de América Latina, al recoger las expresiones de inconformismo social que marcaron su época de apogeo entre los años 60 y 80 (cuando la izquierda ganaba terreno político como resultado del subdesarrollo, la creciente miseria, el descontento de la población y la falta de liderazgo de los mandatarios de la región, quienes fueron incapaces de plantear alternativas que permitieran superar estas problemáticas). La canción social se alimentó de la lírica universitaria, del sindicalismo, de las injusticias cotidianas, alentando la lucha por ideales, poderes y pertinencias, con un vocabulario y expresión acordes. El género decae hacia los años 80 como consecuencia de las crisis económicas y la llegada de las dictaduras, y su silenciamiento, así como el asesinato o exilio de sus intérpretes, acompaña la estrangulación de cualquier anhelo de cambio revolucionario en el continente.
\end{abstract}

\section{PALABRAS CLAVES}

Canción protesta, descontento, sindicalismo, luchas sociales, música, movimientos sociales.

\section{UIRSIAIKUNAWA IACHARI MANA ALLILLA KAGTA POLITIKAPI XX WATAKUNAPI}

\section{SUGLLAPI}

Kaipi maestría ima Niriagta 1960- 1970 imasa kagta Colombiapi watakunapi america Latinapi chi watakunapi 60- 80 vincikurka llukikunaa sugrigcha kawachingapa pueblokunata mana sumarkakunata chasakuna, religiónpi mana pudirkuna allilla tukungapa tukuikuna.

IMA SUTI RIMAI SIMI:

Virsiaikunawa, mana allilla, sindicalismo, lucha social, virsiakuna, gintikunapa iuiai.

\section{PROTEST SONG AS AN EXPRESSION OF SOCIAL AND POLITICAL DISSENT IN THE 2OTH CENTURY}

\begin{abstract}
This article, stemming from the master's thesis "The Social and Political Imaginary in the Social or Protest Song in Colombia during the period of 1960 to 1970", shows the important role that protest song has played in the history of Latin America in collecting the expressions of social dissent that marked its heyday from the 60s into the 80 s (when the left won political ground as a result of underdevelopment, increasing poverty, the discontent of the population and the lack of leadership from the heads of state of the region, who were unable to propose solutions that would overcome these problems). The protest song fed from university poetry, from trade unionism and from daily injustices, encouraging the fight for ideals, empowerment and the urgent, with the vocabulary and expressions that best suited them. The genre decayed during the 80 s as a result of the economic crises and the advent of dictatorships; its silencing, as well as the murder or exile of its performers, accompanied the death of every hope for revolutionary change on the continent.
\end{abstract}

\section{KEYWORDS}

Protest song, discontent, unionism, social struggles, music, social movements. 


\section{LA CHANSON SOCIALE COMME EXPRESSION DE LA NON-CONFORMITE SOCIALE ET POLITIQUE AU XXE SIECLE}

\section{RÉSUMÉ}

Cet article, produit du mémoire de Master sur « L'imaginaire social et politique présent dans la chanson sociale ou de protestation en Colombie pendant la période 1960-1970 », montre le rôle prépondérant que la chanson engagée a joué dans l'histoire de l'Amérique latine, en rassemblant les expressions de non-conformisme social qui ont marqué à l'époque de leur apogée entre les années 60 et 80 (quand la gauche gagnait du terrain politique suite au sous-développement, à la misère croissante, au mécontentement de la population et au manque de leadership des mandataires de la région, ceux qui ont été incapables de poser des alternatives qui permettraient de dépasser ces problématiques]. La chanson sociale s'est nourrie de la lyrique universitaire, du syndicalisme, des injustices quotidiennes, en encourageant la lutte pour des idéaux, des pouvoirs et des pertinences, avec un vocabulaire et une expression concordants. Le genre dépérit vers les années 80 suite aux crises économiques et à l'arrivée des dictatures, et son étouffement, ainsi que le meurtre ou l'exil de ses interprètes, accompagne l'étranglement de toute aspiration de changement révolutionnaire dans le continent.

\section{MOTS CLÉs}

Chanson engagée, mécontentement, syndicalisme, luttes sociales, musique, mouvements sociaux.

\section{A CANC̣ÃO SOCIAL COMO UMA EXPRESSÃO DE INCONFORMISMO SOCIAL E POLIITICA NO SÉCULO XX}

\section{RESUMO}

Este artigo, produto da tese de mestrado "El imaginario social y político presente en la canción social o protesta en Colombia durante el periodo comprendido de 1960 - 1970", (0 imaginário social e político presente na mùsica social ou de protesto na Colômbia durante o período compreendido de 1960 - 1970. Mostra o papel importante que a música de protesto tem desempenhado na história da América Latina, para recolher expressões de inconformismo social que marcou o seu auge na década de 60 e 80 anos ( quando a esquerda ganhou terreno político como resultado do subdesenvolvimento, crescimento da miséria, o descontentamento da população e a falta de liderança dos líderes da região que eram incapazes de propor alternativas que permitiam superar esses problemas) A mùsica social foi alimentada da lírica universitária, do sindicalismo, das injustiças diárias, encorajando a luta pelos ideais, poderes e relevância com um vocabulário e expressão acordes. 0 decaimento do gênero foi nos anos 80 como consequência das crises econômicas e a chegada das ditaduras, silenciamento, assim como o assassinato ou exílio dos intérpretes, acompanha estuangulamento de qualquer desejo de mudança revolucionária no continente.

\section{PALAVRAS CHAVES}

Canção de Protesto , o descontentamento, o sindicalismo, lutas sociais, música, movimentos sociais. 
Las artes como la música, la poesía, la escultura, la pintura y la danza, entre otras, son expresiones de la cultura de un pueblo y se han constituido en la forma como el artista comunica sus ideas y sentimientos con palabras, formas, colores o sonidos. El artista concibe y produce lo bello a partir de los elementos naturales que tiene a su alcance y que ha adquirido de la observación y estudio. Las artes son el medio por el cual el individuo se relaciona con el mundo; también son entendidas como una actividad o producto con una finalidad estética y comunicativa implícita que les permite a los humanos expresar ideas, emociones o visiones del mundo, haciendo uso de recursos plásticos, lingüísticos, sonoros o mixtos. La forma como se expresan los sentimientos en las artes se debe al hecho, como lo señala el poeta español Blas Otero (1916-1979) de que "las realiza el hombre con sus manos".

Ahora bien, del artículo “¿Qué es el arte?” (BLAA, s.f.) podemos extraer que conceptualmente este puede ser definido tanto a partir de lo útil (albañilería, carpintería y las demás artes manuales o industriales] como a partir de lo bello (pintura, escultura, música, arquitectura y literatura): El arte como utilidad satisface las necesidades materiales y se hace extensivo a la mayoría de profesiones humanas; y el arte como belleza realiza lo bello en sus diversas manifestaciones, de ahí que reciba la denominación de Bellas Artes. Pero no solo el arte es útil y bello, sino que en medio de los dos se encuentran las artes mixtas, que serían la combinación de lo útil con lo estético.

De acuerdo con lo anterior y partiendo del hecho de que el arte es necesario tanto para el individuo como para el conjunto de la sociedad se pueden establecer algunas de sus funciones (La Guía, s.f.):

- Estética: le permite al individuo expresar sus necesidades interiores y sus sensibilidades emocionales.

- Utilitaria: por ejemplo en la arquitectura, cuya función es crear un espacio artificial para ser habitado.

- Mágica: porque le son atribuidos "poderes"; el ejemplo más claro se puede apreciar en la pintura rupestre del paleolítico, donde se le atribuyen al objeto representado "poderes" con la finalidad de capturar el espíritu del animal para que la cacería sea productiva; de igual forma la función mágica del arte se daba en los ritos funerarios, ritos de fertilidad o de guerra, etc.

- Didáctica: característica de las culturas iletradas donde la imagen sustituye las palabras cuando de instruir a una persona se trata. En esta función el mensaje es transmitido de forma directa y es de fácil comprensión.

- Persuasiva: a diferencia de la anterior en esta función se involucra al receptor con las imágenes, buscando convencerlo.
- Ideológica: Se transmite un pensamiento social o político y por medio de una imagen de poder se expresa una justificación y/o una defensa.

De acuerdo con la finalidad al usar su poder comunicativo y expresivo, se puede reconocer en las artes varias formas peculiares de lenguaje. El lenguaje hablado o escrito facilita un tipo de comunicación, de intercambio de ideas más rápido y directo y, a la vez, proporciona o sugiere un rico mundo de imágenes mentales. El lenguaje de las artes es más indirecto debido a que los mensajes del artista, por medio de su obra, no siempre se captan de manera inmediata. Para ello es preciso conocer un poco las claves de interpretación propias de cada arte en particular.

El lenguaje de la música resulta ser uno de los más inconcretos e indeterminados, pero a su vez de los más atractivos y sugerentes pues nos sumerge en un inacabable mundo de emociones y fantasías; es decir que es más fácil transmitir un mensaje de forma oral que escrita, puesto que puede ser captado por cualquier tipo de oyente sin importar su nivel sociocultural (Méndez, 1994: 16).

En concordancia con lo anterior y partiendo del enunciado de que los imaginarios de la canción protesta durante el período comprendido entre 1960 y 1970 en Colombia representan unas particulares condiciones sociales y políticas, el propósito de la investigación se basó en establecer los imaginarios particulares de un grupo de canciones recogidas bajo el nombre de canción protesta o canción social, que para el caso que nos ocupa, fueron usadas como discursos, teniendo en cuenta que las canciones pueden ejercer un efecto ideológico en sus escuchas, a través del contenido de sus textos en situaciones y contextos sociales particulares; esta persuasión ideológica logra cambiar actitudes e influir en las creencias sociales y cogniciones personales de sus receptores por medio de discursos en donde las estructuras, estrategias y funciones son dispuestas de forma que el oyente termina por evaluar las proposiciones y representaciones de la forma en que lo determine el emisor, es decir, la función ideacional representa el significado del hablante como observador del contenido del lenguaje (Lara 2006: 68).

Pero no solamente el lenguaje de la música es tan atractivo y sugerente que despierta todo un mar de emociones y fantasías; el lenguaje poético aviva por igual una experiencia humana y sensualmente significativa. De ahí que poetas como Gabriel Celaya afirmen que la "La poesía es un instrumento, entre otros, para transformar el mundo" y su función es la de innovar la sociedad. Eugenio de Nora le atribuye "una función social como lo es el trabajo o la ley" (citados en la Enciclopedia Larousse. Historia Universal II: 159). 
permitiéndole expresar su participación como hablante en una situación de discurso, compartir con los demás sus deseos, sentimientos, actitudes y juicios; y es gracias al lenguaje como todo aquello que dice o hace lo vincula a un contexto (Halliday, 2001: 26, 33-34).

Ahora bien, el vínculo que se establece entre el lenguaje y los estudios socio-culturales es inmediato; la acción discursiva tiene un papel preponderante en la constitución de la identidad socio-cultural, permitiendo la caracterización de los participantes junto con los tipos de relaciones que estos establecen en el contexto social y en sus procesos enunciativos, de forma que se establecen posiciones en el campo del poder (Lara 2006: 44). De ahí que, en la tesis de maestría, las letras de las canciones fueron tomadas como discursos, puesto que contienen lo que el autor quiere decir; por tanto se analizaron desde las estructuras discursivas establecidas por Calsamiglia y otros (2007): tópicos, léxico, retórica, estrategias y los elementos semióticos de registro (campo, modo, tenor, las personas del discurso) y el contexto en que cada discurso se desarrolló (Halliday, 2001).

Desde otro punto de vista encontramos que la relación entre el lenguaje y la música se da en el entendido que el arte literario no se limita únicamente a mostrar las expresiones del autor, sino que estas son también el reflejo de la sociedad; igual situación ocurre con la música que trasciende más allá de la mera expresión artística, convirtiéndose en el medio de expresión del acontecer social, tanto de autores como oyentes, en un contexto determinado, y permite luego, a través del análisis de estos (literatura y música), ver sus realidades e imaginarios. El artista proyecta su realidad histórica y cultural, que se encuentra presente en las correlaciones de las estructuras sociales y las representaciones colectivas. Un botón de muestra es el caso colombiano, donde hacia la década de los 70 la música y la literatura revelan el inconformismo generalizado ante una realidad social.

Retomando el tema de la utilización de la canción protesta como expresión de descontento por parte de los sindicatos, cabe señalar que no fueron estos los únicos que utilizaron la música como manifestación clara de su inconformidad con las estructuras económicas, políticas y sociales, sino que también lo hicieron los grupos que se oponían a la guerra y la segregación racial, como las sit-ins (sentadas), integradas por negros que luchaban en los estados sureños por la igualdad racial; ellos acudían a los sitios reservados exclusivamente para blancos y se sentaban en el suelo negándose a abandonar el lugar, siendo reprimidos sin demora por la policía. A estos grupos de sit-ins se les unen los blancos que estaban también en contra de las legislaciones segregacionistas. En estas sentadas y marchas confluyen también las canciones y cantantes de música popular o protesta.

\section{La canción protesta en América Latina y Colombia}

En muchos países latinoamericanos en la década de los 60, como consecuencia de sucesos como la Revolución cubana, la Guerra de Vietnam, la muerte del Che Guevara, entre otros, surgió este tipo de canción con alto contenido de mensajes sociales comprometidos. Utilizando la canción como discurso, se pretendía generar un cambio radical en las estructuras sociales, económicas y políticas; se buscaba la unidad de los pueblos latinoamericanos frente a las elites y contra los intereses de las grandes multinacionales en especial las norteamericanas. Para ello sus intérpretes encararon la represión militar, la desigualdad social, la injusticia social y la pobreza, entre otros temas urgentes. Las canciones, a su vez, sirvieron de fuente de inspiración para las luchas de las clases desfavorecidas por ideales, poderes y pertinencias, con un vocabulario y expresión que resonaba en lo más íntimo.

A la par del auge de la canción protesta (conocida también como canción social, popular o anarquista) hacia la década de los años 60, surgen en América Latina grupos de izquierda como respuesta al subdesarrollo, a la creciente miseria, al descontento de la población y a la falta de liderazgo de los mandatarios de la región, quienes fueron incapaces de plantear alternativas que permitieran superar aunque fuera una de estas problemáticas. En Colombia estas canciones recogen temas de pobreza y violencia y en ellas los autores exaltan personajes que rara vez entraban en la escena de lo público: Los niños, las mujeres, el pueblo, los campesinos, los desempleados, los marginados, etc. (Ramírez, 2010).

En los años 60 los jóvenes se constituyeron en un factor de cambio social; expresaban su descontento con la sociedad, fueron rebeldes, capaces de enfrentarse al Estado y buscaban salidas a las problemáticas que los aquejaban; también reclamaban el reconocimiento de sus derechos y la defensa de sus ideas, y no temían romper con la división de clases sociales. En respuesta, el gobierno censuraba todas estas manifestaciones por considerarlas como una amenaza para el orden establecido; hizo a los jóvenes objeto de represión, buscando ahogar toda forma de expresión juvenil e imponiendo su autoritarismo. Como consecuencia de lo anterior el rock va a arropar a la juventud, permitiéndole unirse para defenderse y rebelarse contra todo intento de sometimiento, conformando una nueva identidad que tenía como característica principal "un pensamiento más liberal y revolucionario". Estas expresiones contestatarias, al tiempo que adquirieron fuerza, permitieron la adhesión de las masas que encontraban en las letras de este género musical,

una forma de mostrar su descontento, de rebatir el autoritarismo, de no ser indiferentes ante los problemas que los agobiaban en aquel momento. 
En síntesis el rock fue y ha sido un factor capaz de unir en torno suyo a los jóvenes, de reafirmar identidades, de ser el interlocutor entre la sociedad y la juventud que alza su voz para decirle a la sociedad que existen y tienen presencia dentro de ella y que a toda costa lucharan por mejores condiciones de vida para todos en general (Movimientos Antisistémicos UV).

Hay que reconocer que la Revolución cubana también va a influir en la canción protesta con el movimiento cultural y musical conocido como la Nueva Trova Cubana, al que pertenecieron Pablo Milanés, Lázaro García, Silvio Rodríguez y Noel Nicola, entre otros. Sus letras y actitudes creativas fueron influenciadas por los acontecimientos que rodearon la Revolución cubana de 1959. Este movimiento va a extenderse por Centro y Suramérica; algunos de sus exponentes de una u otra manera estuvieron vinculados con la política de sus países: en Venezuela encontramos a Soledad Bravo y Alí Primera, quien mostró interés porque en su país se optara por un programa político de izquierda (hecho que trajo como consecuencia que sus canciones fueran proscritas). En Chile Inti-lllimani, Quilapayún, Violeta Parra y Víctor Jara fueron piezas claves en la elección de Salvador Allende como presidente en 1970. Recordemos que Allende contribuyó con Cuba en su proyecto expansionista en Suramérica.

Dentro de este contexto en la década de los años 70 en América Latina, dos hechos importantes marcaron su historia: El Concilio Vaticano II, que sesionó en Roma de 1959 a 1965 y el Primer Encuentro de la Canción Protesta, que tuvo lugar en Cuba en la Casa de las Américas en 1967. Estos eventos se van a entrecruzar gracias a la teología de la liberación, que es una de las principales consecuencias del Concilio. En un principio no fue amor a primera vista, ya en que los postulados que proclamaban los grupos de izquierda, en especial en lo referente a la cultura y los aspectos religiosos, había una clara animadversión a las sotanas, vistas como un obstáculo para el desarrollo de América Latina por el poder que ejercen sobre la población (Guerrero Jiménez). Isabel Soto, en su artículo "Catolicismo en América Latina frente al Concilio Vaticano II" plantea como aspectos que también influyeron en la frialdad hacia el clero, los siguientes:

- La imposición a la fuerza de la religión católica por parte de España desde la Conquista.

- La coexistencia de iglesias católicas paralelas y a la vez diferentes entre sí: La del negro y la del amo, la del indio y la del blanco, la del rico y la del pobre, esta última con un clero foráneo.

- La participación del clero en los círculos de poder oligárquicos y pro imperialistas en los siglos XIX y XX.
- La apatía de las autoridades hacia los oficios religiosos.

- La malquerencia por parte de intelectuales y figuras representativas de los movimientos populares reformadores hacia el cristianismo y todo lo que el clero representaba. Fue el caso de: Bolívar, San Martín, Artigas, Sucre, Moreno en las guerras de independencia. La de la Reforma en México y Venezuela y el positivismo en Brasil, Uruguay, Argentina y Chile; o la de Juárez, José Pedro Varela en Uruguay, o Domingo Faustino Sarmiento en Argentina; todos ellos nacionalizaron cementerios, instituyeron el registro civil e incluso, en algunos casos, liquidaron bienes materiales de la Iglesia. Todo esto vale el doble para "los anarquistas, sindicalistas y socialistas de finales del siglo XIX y principios del XX y sus continuadores más radicales: Los comunistas".

Como se indicó anteriormente, a mediados de los 60 se conjugaron dos eventos importantes para América Latina: El I Encuentro de la Canción Protesta y el Concilio Vaticano II; durante su desarrollo se sucedían paralelamente hechos como:

- El recrudecimiento de las guerras internas como resultado de la marginación, la exclusión, el racismo y la explotación de las poblaciones más pobres, en especial la indígena.

- El cambio de actitud por parte de algunos sectores de la iglesia católica latinoamericana, la cual, como se dijo más arriba, unos siglos antes habían cohonestado la perpetuación del poder colonialista.

- El auge de la canción protesta, considerada en muchos países de América Latina como subversiva, y que en todo el continente despertó sentimientos de identidad y solidaridad, especialmente en países como Argentina, Brasil, Chile, Venezuela y los de América Central.

- En Guatemala el gobierno del General Efraín Ríos Montt impuso el terror y el genocidio; si a alguna persona se le encontraba en su poder música del grupo Los Guaraguao o de los hermanos Mejía Godoy era sometida a toda clase de vejaciones, se le trasladaba ante los tribunales de fuero especial con jueces sin rostro y sin derecho a la legítima defensa.

[Guerrero Pérez, 2005)

Ahora veamos, grosso modo, de acuerdo con Guerrero Pérez, cuáles fueron las principales características de estos dos sucesos (El Encuentro Internacional de la Canción Protesta y el Concilio Vaticano II): 
El nombre de canción protesta se generaliza a partir del I Encuentro Internacional de la Canción Protesta, que mostró un fuerte compromiso con la realidad latinoamericana del momento. De acuerdo con la región donde se producía tenía un nombre distinto, por ejemplo: En Chile en un principio se le conocía como música popular, luego música popular renovada y a partir de 1967 se le llamó Nueva Canción y posteriormente Nueva Canción Chilena. En los inicios de la década del 60 el nombre de canción protesta estaba destinado a países con un fuerte conflicto armado como Nicaragua y El Salvador. Sin importar su nombre, el género se caracterizaría por proclamar mensajes que rechazaban la pobreza, la explotación del hombre por el hombre, la marginación, la exclusión social, la falta de acceso a la educación y la carencia de servicios públicos, entres muchos otros temas.

\section{Antecedentes del I Encuentro Internacional de la Canción Protesta:}

Los primeros brotes de la canción protesta, como las revoluciones, alzamientos e insurrecciones, estuvieron a la orden del día en la segunda mitad del siglo XX: El impacto de la revolución cubana, el mito que giraba alrededor del Che Guevara, la guerra de Vietnam, las dictaduras latinoamericanas, etc., fueron el entorno político en que se llevó a cabo, en 1967, en la Casa de las Américas en Cuba, el I Encuentro Internacional de la Canción Protesta, con los siguientes objetivos:

- Reunir a sus creadores que estaban dispersos, en especial los del Cono Sur.

- La realización de un trabajo colectivo, analítico, político y social en relación al contenido de la canción social.

- Encontrar puntos de contacto con los principios de la generación que iba surgiendo.

- Mantener y fomentar la calidad poéticomusical de la canción popular en los años venideros.

- Generar un nombre para la canción, pero manteniendo las denominaciones propias de cada país o región.

- Perfilar una nueva ética y estética para la canción protesta.

(Kolectivo La Haine, 2002 en Guerrero Pérez, 2005)

\section{Conclusiones del Encuentro:}

- La canción protesta es un arma al servicio del pueblo.
-Debe ser una toma de posición definida por parte de los trabajadores frente a los problemas sociales del pueblo.

-El movimiento de la canción protesta debe estar vinculado a la lucha de la liberación de los pueblos oprimidos.

- La canción protesta debe ser combativa y militante;

-Y debe estar comprometida con las causas sociales.

(Kolectivo La Haine, 2002 en Guerrero Pérez, 2005)

Culminado el Encuentro, se estableció que los objetivos y conclusiones se cumplieron puesto que estas últimas se convirtieron en fines y propósitos a largo y mediano plazo, especialmente gracias a la vinculación del género con la lucha por la liberación de los pueblos oprimidos.

Por su parte el Concilio Vaticano $\|^{2}$ tuvo el propósito de introducir dentro de la iglesia católica algunos cambios doctrinales y litúrgicos y lograr el acercamiento con las iglesias separadas. Fue convocado en 1959 por el Papa Juan XXIII, quien no pudo concluirlo debido a su muerte en 1963; fue retomado por su sucesor, Pablo VI, y clausurado el 7 de diciembre de 1965.

\section{Antecedentes del Concilio Vaticano II:}

- Algunos de los ritos del culto católico tenían elementos del hebraico como vestuario y símbolos.

- El idioma oficial de culto católico era el latín

- En la iglesia católica perseveraron manifestaciones del rito mozárabe, del galicano y ritos propios de las órdenes monásticas.

- El canto ritual principal eran el gregoriano o canto llano que se acompañaba, como único instrumento, con un órgano de viento.

2. El I Concilio Vaticano I fue convocado por el Papa Pio IX y llevado a cabo entre 1869 y 1870 en la Basílica de San Pedro en el Vaticano. Su propósito principal fue enfrentar las corrientes filosóficas agrupadas bajo el racionalismo (según el cual los principios esenciales de la religión son innatos y no es necesaria la revelación) y el galicanismo, que establecía que la iglesia católica debía estar supeditada al Estado; como resultado de este concilio se aprobó como dogma de fe la infalibilidad papal, es decir se reforzaba la autoridad del pontífice. 


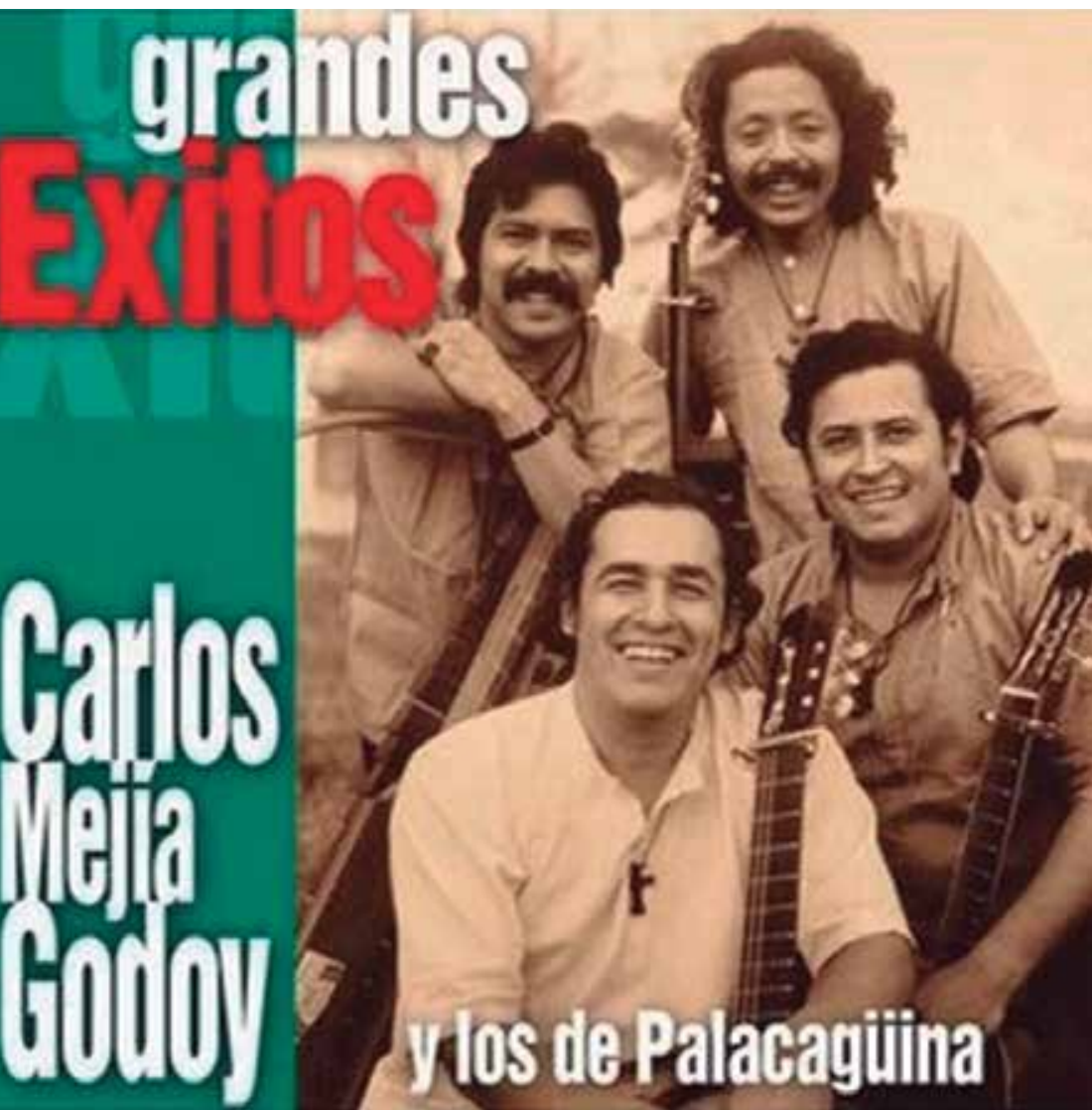

- Grandes éxitos, Carlos Mejía Godoy y los de Palacagüina. Carátula

- Los temas de este tipo de canto eran de alabanza y petición de salvación eterna.

- El final de la Segunda Guerra Mundial trajo como consecuencia la implementación de la Guerra Fría, y el duelo ideológico de comunismo vs. capitalismo.

- En el marco de la Guerra Fría, los cristianos se inclinaron a un materialismo y secularismo que abandonaba a grandes pasos las costumbres y normas de la religión.

\section{La teología de la liberación:}

Esta teología es una combinación de cristianismo y marxismo y tiene su origen en la teología política de Metz, la teología de la esperanza de Moltmann y la filosofía neomarxista de Ernest Bloch, que pregona también la esperanza. En el continente europeo fracasa porque el marxismo desconocía los sacramentos, mientras en Latinoamérica su aplicación no tuvo inconveniente, puesto que la fe va a ser concebida por los teólogos liberadores como un compromiso histórico y la redención como una liberación. La teología de este corte va a ser pensada dentro de la filosofía marxista, que entre otros aspectos hace énfasis en que la riqueza de la élite colonial debía ser redistribuida entre los campesinos pobres para que mejoraran su situación económica; y reconoce

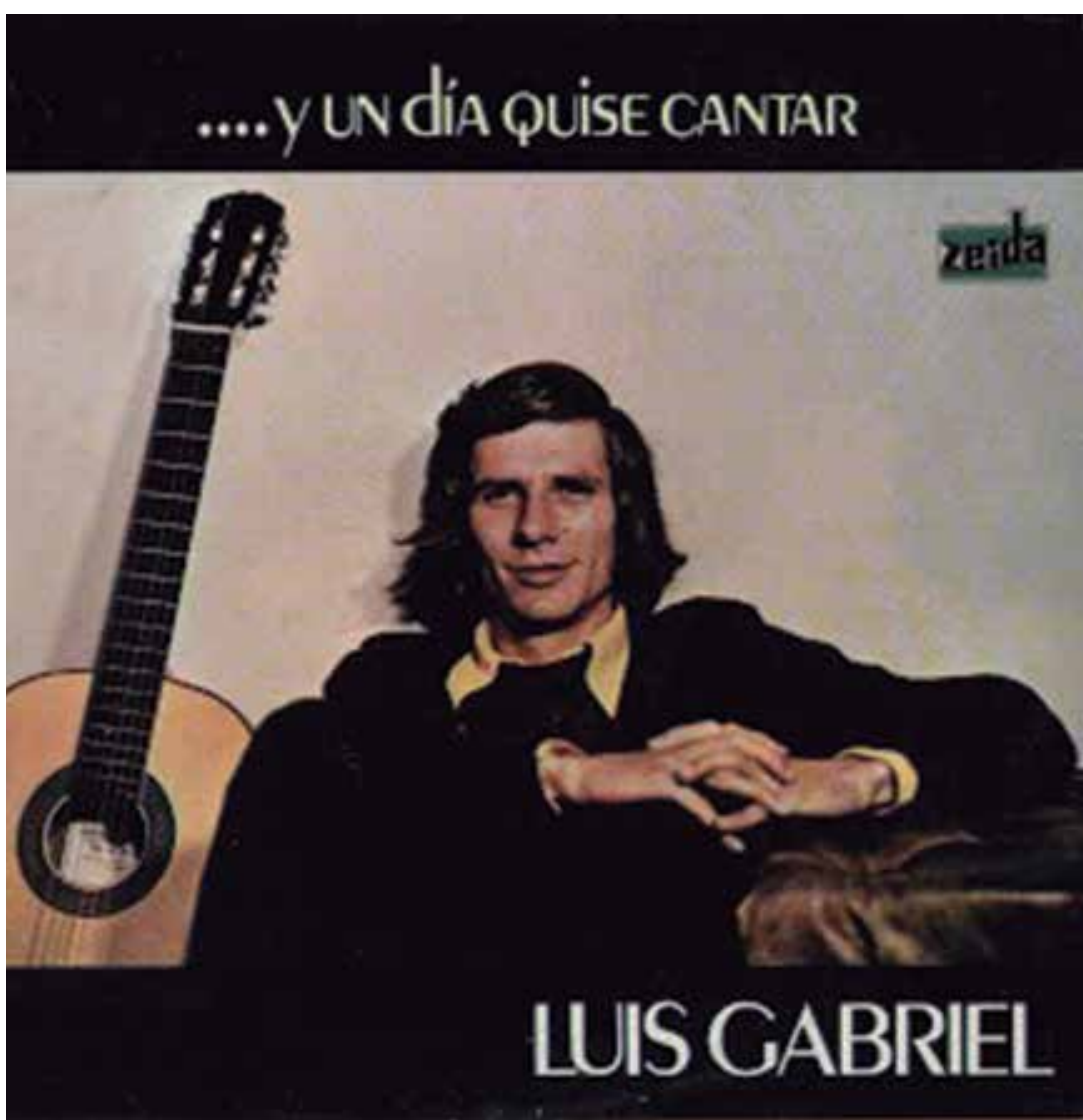

$\Delta$ y un día quise cantar. Luis Gabriel. Carátula

la necesaria la participación del cristianismo en los procesos sociales especialmente en procura de la liberación de las clases bajas oprimidas económica y políticamente. De ahí que la fe se involucró con el momento histórico reconociendo la presencia de Cristo en el pobre, el hambriento, el oprimido, el humilde, el desvalido, el explotado y el marginado.

Ahora bien, a partir del Concilio Vaticano II se suscitan cambios importantes en la iglesia católica latinoamericana:

- El culto católico ya no va a ser en latín sino en español.

- Los cantos gregorianos se transforman en cantos con mensajes acordes con las circunstancias socio-políticas por las que atravesaba Latinoamérica en ese momento.

- Se da un cambio profundo en la forma en que es percibido el cristianismo, que le da más cabida a los valores de la modernidad.

- Hubo un reacomodo de toda su doctrina que contribuyó al acercamiento con otras iglesias cristianas, con otras religiones, ateos y comunistas. 


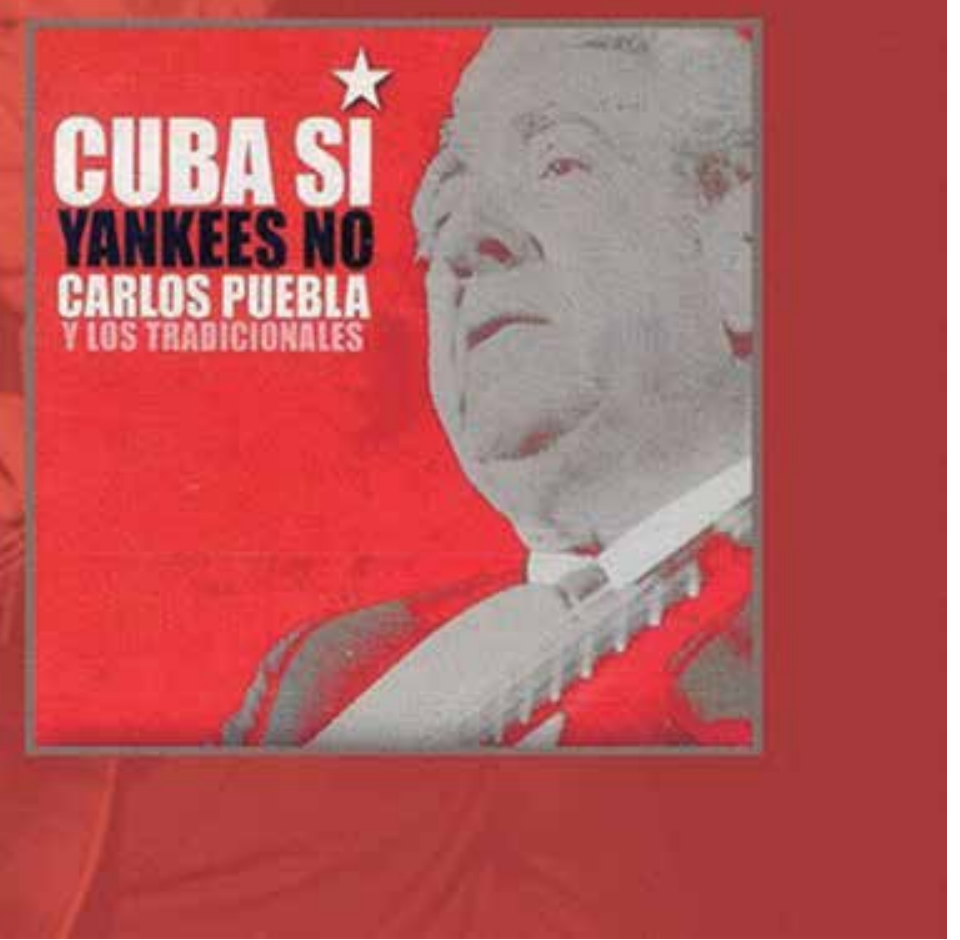

- Cuba sí, yankees no, de Carlos Puebla y los Tradciionales. Carátula

- Las misas van a ser más participativas.

-Los temas de las homilías, en las iglesia católicas, van a versar sobre la situación que enfrentaban los habitantes de América Latina.

Finalmente hay que decir que así como hubo puntos discordantes entre la izquierda latinoamericana y la religión en los inicios de la canción protesta, otras circunstancias permitieron su acercamiento, entre ellas: La llegada de los cantos litúrgicos con expresiones de protesta; la vinculación de algunos religiosos de diversas maneras en la resistencia cívica y la lucha en las montañas (como fue el caso del sacerdote colombiano Camilo Torres, quien dejó la sotana para unirse a la guerrilla); la actitud tomada por la iglesia católica en Chile en defensa de los derechos humanos.

A partir del Concilio Vaticano II, no era raro escuchar en los templos cánticos con mensajes reivindicativos, como por ejemplo:

\section{Danos un carazón}

(Juan A. Espinosa)

Danos un corazón, grande para amar. Danos un corazón, fuerte para luchar.

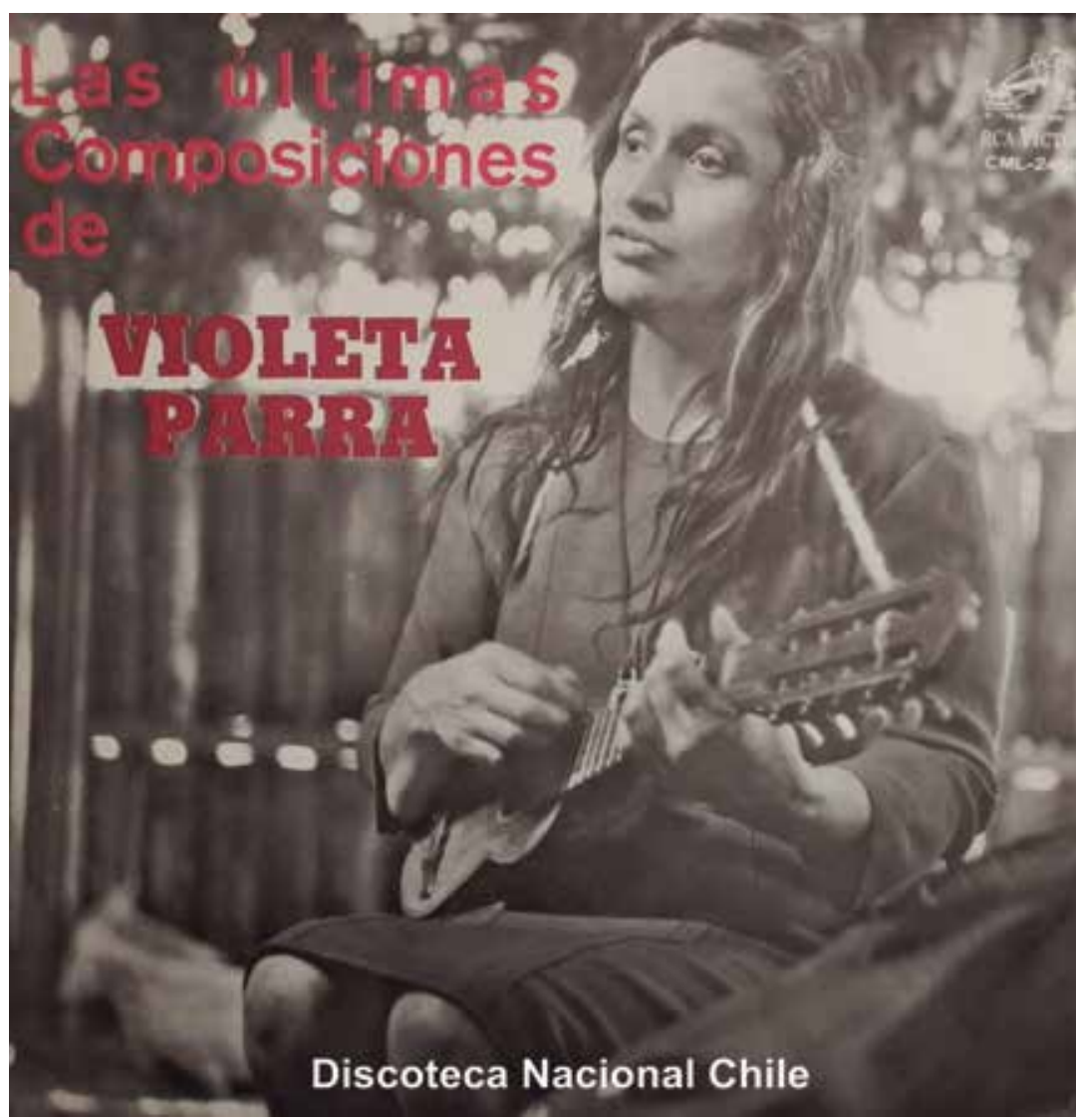

- Las ultimas composiciones de Violeta Parra. Carátula. Discoteca Nacional de Chile

Pueblos nuevos, creadores de la historia, constructores de nueva humanidad.

Pueblos nuevos, que viven la existencia como riesgo de un largo caminar.

Pueblos nuevos, luchando en esperanza, caminantes, sedientos de verdad...

\section{Canto de entrada}

Misa campesina nicaragüense

[Autor: Carlos Mejía Godoy]

"Vos sos el Dios de los pobres, el Dios humano y sencillo, el Dios que suda en la calle, el Dios de rostro curtido. Por eso es que te hablo yo así como habla mi pueblo, porque sos el Dios obrero, el Cristo trabajador..."

\section{Madre de los pobres}

Madre de los pobres, los humildes y sencillos, de los tristes y los niños que confían siempre en Dios... 
También a nuestro país arribó lo que se conoce como la Nueva Ola, que va a imponer una nueva forma de vestir en los jóvenes (la minifalda, el cabello largo y los zapatos de plataforma para los hombres), el juego del hula-hula, junto a la llegada al país de ritmos americanos como el twist, el rock and roll ${ }^{3}$, melodías difundidas a través de los medios de comunicación. Pero contrario a la canción de protesta que expresaba inconformidad con la situación que se vivía en Latinoamérica, y donde sus cantantes asumían un compromiso ideológico, las canciones de la Nueva Ola eran consideradas como banales, como canciones consumistas, que deformaban el gusto y estaban destinadas a mantener el estado de cosas.

Colombia no fue ajena, en la década de los 50 y 60 , a los sucesos que azotaban al mundo y América Latina. En lo que concierne a la desigualdad social, el surgimiento de los grupos de izquierda, como las FARC (Fuerzas Armadas Revolucionarias de Colombia) de inspiración soviética, y el ELN (Ejército de Liberación Nacional), con influencia cubana, el M-19, en protesta por la derrota electoral de la ANAPO en 1970 y los nacientes conflictos urbanos. Gabriel García Márquez, con sus obras La hojarasca y La mala hora, relata la violencia que para la época se vivía en Colombia. La canción protesta llegó a nuestro país de la mano de artistas como los hermanos Ana y Jaime Valencia, Pablus Gallinazus (seudónimo de Gonzalo Navas Cadena), Eliana, Luis Gabriel, entre otros, para denunciar la miseria, la represión y violencia político-social, el empobrecimiento, el éxodo del campesino a la ciudad, el desempleo, la segregación racial y el abuso de autoridad que aquejaban al país. Veamos algunas estrofas de las canciones más reconocidas:

\section{Mi país \\ (Autor: Pablus Gallinazus. Intérpretes: \\ Ana y Jaime]}

"Con un poco de humor, vamos a reír de la situación, de nuestro país

Con un poco de humor y un pañuelo en la mano vamos a reír de la situación de mi país.

Ni grande ni chico es mi país,

se habla el español se come maíz

Así adivina tú, adivina tú cual es mi país. Hay diez policías, por cada estudiante y hay un estudiante, por mil ignorantes..."

La mula revolucionaria

[Autor: Pablus Gallinazus]

Baja una mula del monte viene montando Ramón mula revolucionaria, baja la revolución (bis)"...
Si bajan los guerrilleros, maten al buey (bis) que ellos aran caminando y entonces el buey páque (bis)

Ricardo semillas

(Autor: Nelson Osorio. Intérpretes: Ana y Jaime]

"Ricardo reunió a los hombres y les habló con despacio palabras verde esperanza teñidas de sal y selva, les dijo la vida es nuestra, también es nuestra la tierra y las palabras que traigo son semillas también nuestras ay ay ay ay son semillas también nuestras (bis)"...

\section{Ayer me echaron del pueblo} [Autor: José A. Morales]

"Ayer me echaron del pueblo porque me negué a jirmar, la sentencia que el alcalde a yo me hubo de implantar, porque tuve con mi mano al patrón que castigar, cuando quiso a mi jamilia, quiso a mi jamilia llegármela a irrespetar"...

Además del contenido reivindicativo en estas canciones vamos a encontrar símbolos como: Representación y crítica social, burla, denuncia, quejas; auto-reconocimiento de dominantes y dominados, conflicto, rebeldía, libertad, desigualdad social, desplazamiento, abuso de autoridad, coraje, y dentro de los valores: Vida, arraigo, trabajo, unidad familiar, dignidad, justicia, esperanza y verdad.

Finalmente, hay que decir que la canción protesta va a decaer 20 años más tarde, a mediados de los años 80, como consecuencia de las crisis económicas y especialmente de la llegada a Latinoamérica de las dictaduras, situación que desencadenó en el silenciamiento de las canciones, el ahogamiento de cualquier anhelo de cambio revolucionario, y el asesinato o exilio de artistas. Sin embargo, no pudieron extinguirla del todo, porque aún hoy en día estas composiciones acompañan las marchas de los diversos movimientos que rechazan, entre otros aspectos, la globalización, la explotación de los pobres, las desigualdades sociales, etc.

Ahora, en pleno siglo XXI, cuando la humanidad ha hecho progresos tecnológicos inimaginables y han transcurrido aproximadamente 50 años del surgimiento de los primeros grupos de izquierda en Latinoamérica y de la canción protesta, a mi modo de ver es poco lo que los gobiernos en América Latina y en Colombia han avanzado para superar la miseria,

3. El rock and roll y el juego del hula-hula fueron prohibidos porque se temía que algunos de sus movimientos insinuaban o podían conducir al acto sexual. 
el subdesarrollo, la explotación del hombre por el hombre, el desplazamiento forzoso, etc. Por ejemplo, en nuestro país encontramos comunidades que carecen de servicios públicos, de vías de acceso, que son explotadas laboralmente, que son víctimas de desplazamiento, tanto por grupos alzados en armas, como por agentes del Estado. Aún encontramos en Latinoamérica dictaduras como la cubana y la venezolana, que se disfraza de democracia. Los movimientos sociales todavía están presentes en las calles, exigiendo mejores condiciones laborales y sociales para todos. Es decir, estamos como al principio, aun cuando hay que reconocer que ha habido algunos avances, como la llegada a la primera magistratura por elección popular de exintegrantes de grupos guerrilleros o de movimientos sociales, como es el caso de José Mujica en Uruguay, quien en los años sesenta perteneció al grupo guerrillero Movimiento de Liberación Nacional-Tupamaro. Mujica ejerció la presidencia de 2010 a 2015 luego de haber sido diputado, senador y ministro. Michelle Bachelet hizo parte del gobierno de Unidad Popular dirigido por Allende; posteriormente ingresó a las filas del Partido Socialista, fue víctima de represión por parte de la dictadura de Pinochet y finalmente asumió la Presidencia de Chile de 2006 a 2010; posteriormente volvió a presentarse como candidata presidencial, habiendo sido reelegida en marzo de 2014. En Colombia han desempeñado cargos de elección popular Antonio Navarro Wolf y Gustavo Petro Urrego (ex militantes del grupo guerrillero M-19), como senadores de la República y alcaldes de Pasto y Bogotá, respectivamente. Por último, en la actualidad el gobierno de Juan Manuel Santos se encuentra negociando el proceso de paz con las FARC en la Habana y adelanta exploraciones con el ELN, Ejército de Liberación Nacional, a fin de poder entablar con ellos también acercamientos para dar inicio a conversaciones de paz; ojalá estos diálogos prosperen y así se evite prolongar el derramamiento de sangre que por más de 50 años ha azotado al país.

\section{Referencias}

Biblioteca Luis Ángel Arango (s.f.). “¿Qué es el arte?” Disponible en: http://www.banrepcultural.org/blaavirtual/ayudadetareas/ arte/que_es_arte.

Caneo, Luis Felipe (2010). Revolución cubana, causas y consecuencias. Disponible en: elamaule.cl.

Calsamiglia Blancafort, Helena y Amparo Tuson Valls (2007). Las cosas del decir: manual de análisis del discurso. España: Editorial Ariel.

Cuartas Correa, María Paola. "Relaciones entre la literatura y la música con respecto a la complejidad cultural en Colombia desde los años 70 hasta ahora". Disponible en: centrodedocumentacion.es.

Enciclopedia Larousse. Historia Universal II. Vol. 2. Buenos Aires: Ed. Larousse.

Guerrero Pérez, Juan José (2005). “La canción protesta latinoamericana y la teología de la liberación". En: Estudio de género musical y análisis de vínculo sociopolítico y religiosos. Caracas Monte Ávila Editores.

Guerrero Jiménez, Bernardo (1994). "Religión y canción de protesta en América Latina; un ensayo de interpretación. Revista de ciencias sociales" Chile: Universidad Arturo Prat. Disponible en: www.revistacienciasociales.cl.

Halliday, M.A.K. (2001). El Lenguaje como semiótica social, la interpretación social del lenguaje y del significado. México: Fondo de Cultura Económica.

La Guía (s.f). "La función del arte". (Artículo en línea) Disponible en: arte.laguia2000.com/general/la-funcion-del-arte.

Lara Romero, Gladys (2006). "Lenguaje e interpretación sociocultural”. En: Bravo León, Fernando, et. al. Discurso e imaginario, poder e identidad. Posibilidades de la interdisciplina en la investigación social. Bogotá: Fondo de Publicaciones de la Universidad Distrital.

Méndez Viejo, Fernando (1994). El lenguaje musical. Ediciones Jucar.

Movimientos Antisistémicos UV. (Artículo en línea). Disponible en: <antisistemicosuv.blogspot.com/>

Nárval, Joe (2002). La huella de los años sesenta. Colombia: Ed. El Autor.

Pardo, José Ramón (1985). El canto popular. Barcelona: Salvat editores

Ramírez Sánchez, Nohora Aydeé (2010). "Pobreza y violencia en la canción protesta colombiana". En: Revista Interacción No. 32. Bogotá: Centro de Comunicación Educativa Audiovisual ONG. Disponible en: www.cedal.org.co/index.shtml.

Riaño, Pilar (1991). "Descifrando la cultura popular, investigación participativa en los barrios". En: Revista Controversia, No. 166. Bogotá: CINEP. 
Robayo Pedraza, Miryam Ibeth. El Imaginario social y político presente en la canción social o protesta en Colombia durante el período comprendido de 1960 - 1970. (Monografía para optar al título de Magíster en Investigación Social Interdisciplinaria). Bogotá: Universidad Distrital Francisco José de Caldas. Facultad de Ciencias y Educación.

Sopena, Ramón (1978). Aristos Diccionario llustrado de la Lengua Española. Barcelona: Edit. Sopena.

Soto Mayedo, Isabel. "Catolicismo en América Latina frente al Concilio Vaticano II". Disponible en: isabelsotomayedo.blogia. com/.../032301-catolicismo-en-america-latina.

Wikipedia Enciclopedia Libre. "El arte" (Artículo en línea). Disponible en: es.wikipedia.org/Arte.

www.cancionesdelayer.com 


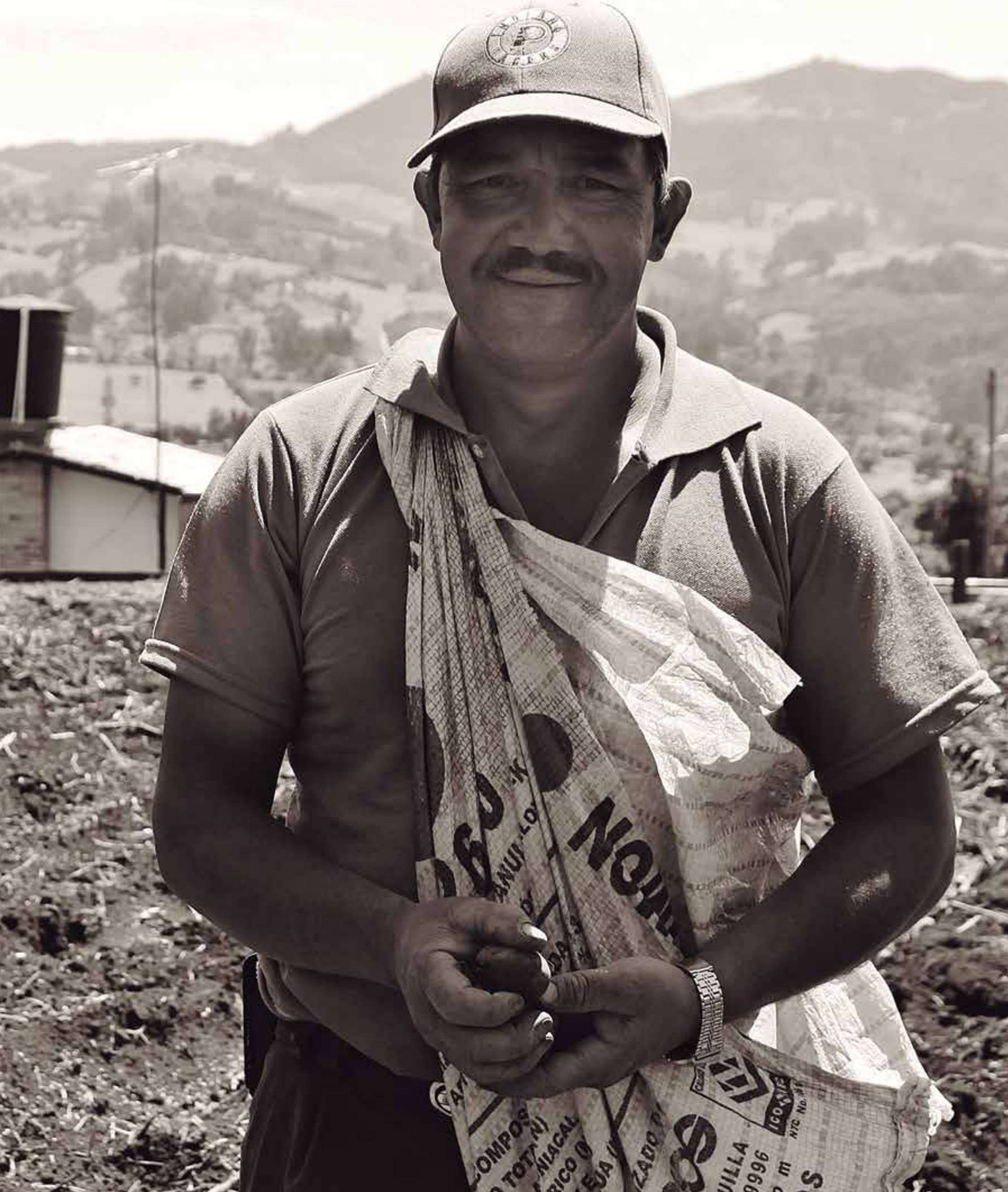




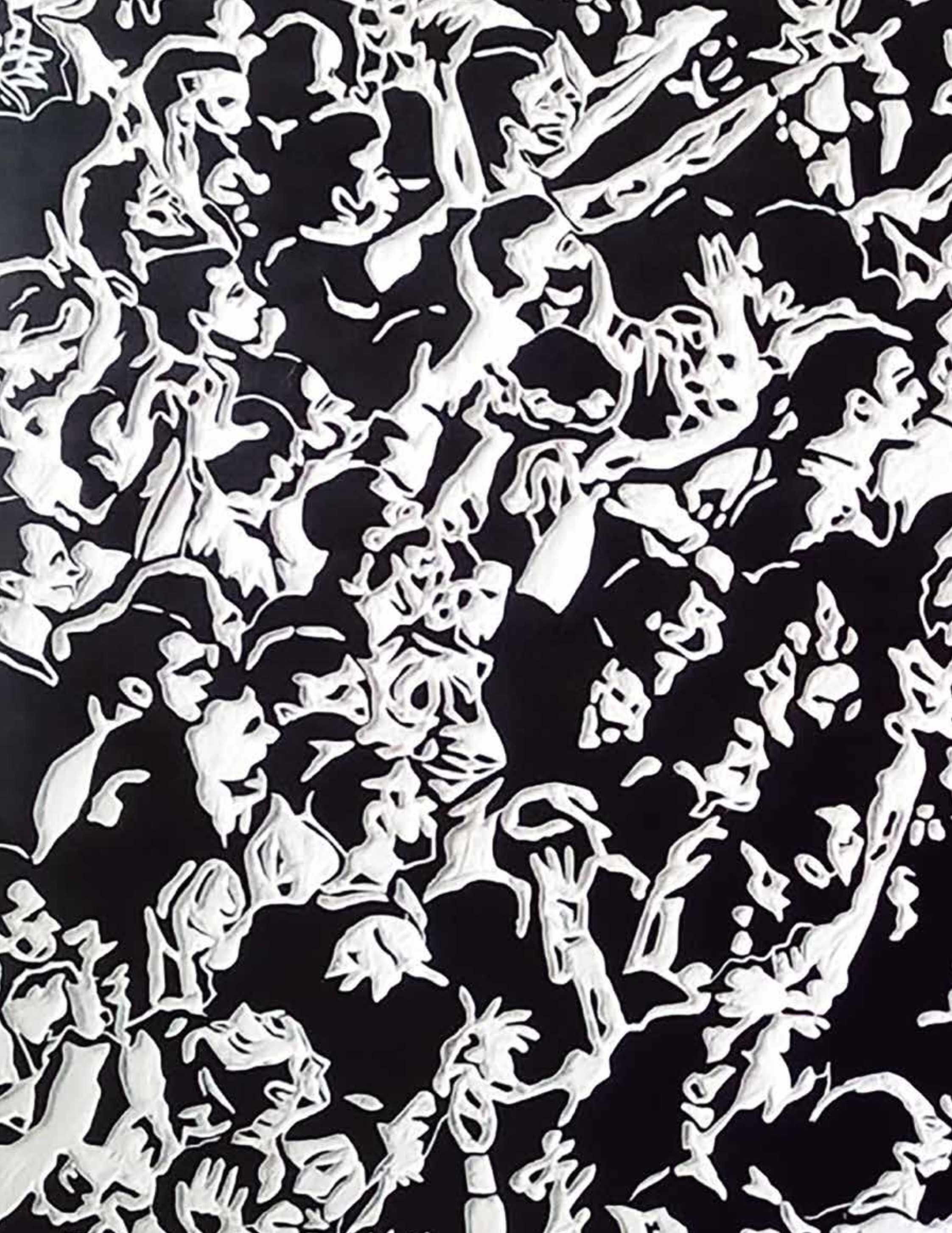


